NBER WORKING PAPER SERIES

\title{
EXPECTED HEALTH EFFECTS OF REDUCED AIR POLLUTION FROM COVID-19 SOCIAL DISTANCING
}

\author{
Steve Cicala \\ Stephen P. Holland \\ Erin T. Mansur \\ Nicholas Z. Muller \\ Andrew J. Yates \\ Working Paper 27135 \\ http://www.nber.org/papers/w27135
}

\author{
NATIONAL BUREAU OF ECONOMIC RESEARCH \\ 1050 Massachusetts Avenue \\ Cambridge, MA 02138 \\ May 2020
}

We thank Robert Burnham, Iván Higuera-Mendieta, and Nicholas Taborsky for research assistance. Cicala gratefully acknowledges support from the Political Economics Initiative at the Becker Friedman Institute at the University of Chicago. The views expressed herein are those of the authors and do not necessarily reflect the views of the National Bureau of Economic Research.

At least one co-author has disclosed a financial relationship of potential relevance for this research. Further information is available online at http://www.nber.org/papers/w27135.ack

NBER working papers are circulated for discussion and comment purposes. They have not been peer-reviewed or been subject to the review by the NBER Board of Directors that accompanies official NBER publications.

(C) 2020 by Steve Cicala, Stephen P. Holland, Erin T. Mansur, Nicholas Z. Muller, and Andrew J. Yates. All rights reserved. Short sections of text, not to exceed two paragraphs, may be quoted without explicit permission provided that full credit, including () notice, is given to the source. 
Expected Health Effects of Reduced Air Pollution from COVID-19 Social Distancing Steve Cicala, Stephen P. Holland, Erin T. Mansur, Nicholas Z. Muller, and Andrew J. Yates NBER Working Paper No. 27135

May 2020

JEL No. Q4,Q5

\begin{abstract}
$\underline{\text { ABSTRACT }}$
The COVID-19 pandemic resulted in stay-at-home policies and other social distancing behaviors in the United States in spring of 2020. This paper examines the impact that these actions had on emissions and expected health effects through reduced personal vehicle travel and electricity consumption. Using daily cell phone mobility data for each U.S. county, we find that vehicle travel dropped about $40 \%$ by mid-April across the nation. States that imposed stay-at-home policies before March 28 decreased travel slightly more than other states, but travel in all states decreased significantly. Using data on hourly electricity consumption by electricity region (e.g., balancing authority), we find that electricity consumption fell about six percent on average by mid-April with substantial heterogeneity. Given these decreases in travel and electricity use, we estimate the county-level expected improvements in air quality, and therefore expected declines in mortality. Overall, we estimate that, for a month of social distancing, the expected premature deaths due to air pollution from personal vehicle travel and electricity consumption declined by approximately 360 deaths, or about $25 \%$ of the baseline 1500 deaths. In addition, we estimate that $\mathrm{CO} 2$ emissions from these sources fell by 46 million metric tons (a reduction of approximately $19 \%$ ) over the same time frame.
\end{abstract}

Steve Cicala

Harris School of Public Policy

University of Chicago

1155 East 60th Street

Chicago, IL 60637

and NBER

scicala@uchicago.edu

Stephen P. Holland

Bryan School of Business and Economics University of North Carolina, Greensboro

P.O. Box 26165

Greensboro, NC 27402-6165

and NBER

sphollan@uncg.edu

Erin T. Mansur

Dartmouth College

100 Tuck Hall

Hanover, NH 03755

and NBER

erin.mansur@dartmouth.edu
Nicholas Z. Muller

Department of Engineering, and Public Policy

Tepper School of Business

Carnegie Mellon University

4215 Tepper Quad

5000 Forbes Avenue

Pittsburgh, PA 15213

and NBER

nicholas.muller74@gmail.com

Andrew J. Yates

Department of Economics

and Curriculum for the

Environment and Ecology

University of North Carolina at Chapel Hill

CB 3305

Chapel Hill, NC 27599

ajyates@email.unc.edu 


\section{Introduction}

The novel coronavirus outbreak, along with measures intended to contain the spread of COVID-19, resulted in significant, and in some cases, unprecedented, changes in society. Because of these alterations to daily life, demand for numerous goods and services fell precipitously from late February through the present. Evidence of the far-reaching effects of social distancing, retail closures, and, generally, reductions in economic activity, is perhaps most obvious in weekly unemployment claims which exceed those during the Great Recession by a factor of ten. Equally evocative is the collapse of oil prices.

In a fossil fuel-based economy such as the U.S., a large adverse demand shock is likely to have appreciable repercussions for emissions and ambient pollution levels. Though long-run outcomes are not yet discernible, it is feasible to assess near term changes in certain measures of environmental quality. Further, because there is an established literature linking exposure to ambient pollution to various health outcomes, it is possible to gauge the effects of such changes on public health. The goal of this analysis is to quantify the health effects of these unprecedented changes from two channels: reduced travel and electricity consumption. This quantification is an important input in an economic analysis of social distancing.

Our analysis uses cell phone data, which are reported daily for every U.S. county, to measure changes in mobility, and by extension, vehicle-miles traveled, over the February to April, 2020 period. For electricity, we employ hourly data by electricity region (e.g., balancing authority) to estimate the changes in electricity consumption, and the corresponding emissions, over the same time period controlling for observable factors such as temperature and a battery of temporal fixed effects. We focus on reductions in emissions that contribute to the formation of fine particulate matter $\left(\mathrm{PM}_{2.5}\right) .{ }^{1}$ In recent years, emissions from travel and electricity generation account for between $25 \%$ and $50 \%$ of national totals depending on pollution species. ${ }^{2}$ We use integrated assessment modeling to connect emissions to changes in ambient $\mathrm{PM}_{2.5}$ and the associated reductions in expected adverse health effects from exposure to pollution. Of particular interest are reductions in $\mathrm{PM}_{2.5}$-associated mortality

\footnotetext{
${ }^{1}$ Emitted pollutants tracked in this study include primary $\mathrm{PM}_{2.5}$, sulfur dioxide $\left(\mathrm{SO}_{2}\right)$, nitrogen oxides $\left(\mathrm{NO}_{\mathrm{X}}\right)$, and volatile organic compounds (VOCs).

${ }^{2}$ See Table A in the Appendix.
} 
risk, as this health endpoint contributes the largest share of air pollution damages (Muller, Mendelsohn, and Nordhaus, 2011).

The cell phone data indicates that personal mobility declined about $40 \%$ on average, with larger decreases in states that were early in implementing social distancing measures. The reduction in electricity generation, in contrast, is just $6 \%$ on average. While behavioral responses to COVID-19 and stay-at-home orders induce a large decline in travel, power consumption decreases are smaller, perhaps due to a shift from commercial to residential applications.

We find that reduced travel and electricity generation are associated with a monthly decrease of about 360 deaths from $\mathrm{PM}_{2.5}$ exposure in the contiguous U.S. As a means of comparison, these emission sources contributed about 1500 deaths per month. Further, we estimate that social distancing resulted in approximately 46 million metric tons less $\mathrm{CO}_{2}$ emissions per month, or about $19 \%$ of the 242 million metric tons that are emitted monthly from driving and using electricity.

The bulk of the reduction in deaths, about 315 per month, manifest from the fall in travel. Decreases in nitrogen oxides $\left(\mathrm{NO}_{\mathrm{X}}\right)$ emissions account for the largest share of this reduction, approximately 200 per month. Reductions in deaths are primarily from cities because both baseline vehicle-miles traveled and exposed populations are larger than in rural areas. We estimate that emission reductions from less travel in Los Angeles induce 75 fewer deaths. In New York City, the analogous total is 25 fewer deaths. States with the greatest reductions in deaths from travel emissions include California, New York, New Jersey, Florida, and Illinois. Note that these estimates are a function of the behavioral changes in mobility in response to COVID-19, the implied changes in vehicle miles traveled, population exposure per ton of emissions, and demographics of the exposed population.

Location-specific reductions in deaths from electricity are much lower given the smaller declines in consumption. Emission and reductions in deaths also display a different geographic pattern, with the largest reduction in deaths due to demand changes in the Southeast and Midwest. These estimates of reduction in deaths from electricity generation depend on behavioral changes in power use in response to COVID-19, the likely changes in the op- 
eration of power plants across the country, population exposure per ton of emissions, and demographics of the exposed population.

Upon previewing our central results it is important to underscore two issues. First, the point of this analysis is not to argue that COVID-19 was in any way beneficial. Rather, we are analyzing an unprecedented set of circumstances, and quantifying the associated changes in emissions from two major sectors of the economy to estimate the health benefits that accrue from less reliance on fossil-based transportation and power generation. Second, potential interactions between reduced exposure to $\mathrm{PM}_{2.5}$ and COVID-19 mortality risks are not modeled. Because observed mortality rates are substantially higher during the months covered by this paper, and due to the fact that $\mathrm{PM}_{2.5}$-induced mortality risk is multiplicatively related to baseline risk (Krewski et al., 2009), our estimates may underestimate actual mortality risk reductions.

The novel coronavirus outbreak has occasioned a large outpouring of scientific research including in the field of economics. However, only a limited number of working papers relate to environmental aspects of the coronavirus outbreak. ${ }^{3}$ Our paper contributes most directly to the literature on the determinants and consequences of social distancing policy (Allcott et al. 2020, Briscese et al. 2020, Fang et al. 2020, Friedson et al. 2020, Greenstone and Nigam 2020).

Section 2 describes the data sources and methods for our estimation of the reduction in deaths from reduced travel and reduced electricity consumption. Section 3 describes the results, and Section 4 concludes.

\section{Methods}

Calculating the expected health effects of the reductions in personal vehicle travel and electricity consumption from social distancing has three components: first, estimating the reduction in travel or electricity consumption; second, calculating the resulting reduction in

\footnotetext{
${ }^{3}$ A search of the NBER working paper series for April 2020 revealed that a remarkable 41 out of 151 working papers dealt directly with the coronavirus outbreak. However, none of these working papers address its environmental aspects. Similarly a search of the broader IDEAS/REPEC working paper series yielded 573 results for 2020 , but only seven of these are related to the environmental aspects of the coronavirus outbreak.
} 
emissions; and third, calculating the health effects of the reduction in emissions. To estimate the reduction in travel or electricity consumption, we use estimates of counterfactual travel or electricity usage based on historical data with controls for relevant confounding variables, e.g., weather. Next, estimates of emission reductions are based on emissions rates per unit of travel or on observed emissions from power plants. Finally, the health effects of the reductions in emissions are calculated from the AP3 integrated assessment model. AP3 maps emissions of different primary pollutants from different sources (counties or point sources) into ambient concentrations of secondary pollutants at receptor counties and uses dose-response relationships and county-specific demographics to calculate expected deaths from the emissions. The AP3 model is explained in detail in Clay et. al. 2019. Below we describe the procedure for estimating health effects from reductions in travel and electricity usage in turn.

\subsection{Personal Vehicle travel}

To estimate the health effects of reduced vehicle travel, we first need an estimate of how much travel decreased. Comprehensive data on vehicle miles traveled (VMT) is reported by a variety of state agencies and collected at the national level. However, our analysis requires high frequency data to estimate the effect of social distancing that has only been in effect for a short time. For high-frequency travel data, we turn to Unacast (2020). ${ }^{4}$ Unacast, which specializes in mobility data analysis, created a pro bono COVID-19 Toolkit to help researchers and to raise public awareness of social distancing. Unacast analyzed cell phone mobility data to calculate a percentage reduction in distance traveled for each county. ${ }^{5,6}$

We combine these percentage reductions with county-level estimates of light duty vehicle VMT from the US EPA MOVES model to determine the reduction in VMT in each county. Light duty vehicles include cars, mini-vans, sport utility vehicles (SUVs), and some pick-up

\footnotetext{
${ }^{4}$ Another potential source of high-frequency travel data is from highway monitors. California has the most comprehensive data collection but only covers major highways.

${ }^{5}$ To date, Unacast has not provided information on the time frame over which they estimated counterfactual travel reductions and which control variables they included. In the Appendix, we analyze data from Streetlight, who use an alternative methodology to infer VMT from cell phone mobility data. The results are similar for the two sources.

${ }^{6}$ An important confound might be the concurrent, dramatic fall in gasoline prices. Because the decreasing gasoline price would tend to increase gasoline consumption, our calculations may understate the true effect.
} 
trucks. By applying the Unacast percentage reduction to all light duty vehicles, we are assuming that reductions in travel are proportional across the vehicle classes.

The resulting reduction in light-duty vehicle travel is summarized in Figure 1a which shows the seven-day moving average of the VMT-weighted average reduction across counties for two groups: counties in states that had an early stay-at-home policy in place by March 28 and counties in states that did not (some of which imposed a stay-at-home policy at a later date). ${ }^{7}$ Before early March there is no reduction in VMT, but by the end of March, VMT fell by approximately 40\%. States with early stay-at-home policies reduced travel more than others, however, there is a substantial reduction in travel in all the states. ${ }^{8}$ Since early April, the VMT reduction seems to have stabilized at around a $40 \%$ average reduction. We use the last week of data (from April 11 to April 17) to calculate the reduction in light duty VMT for each county relative to the baseline.

The dramatic reduction in VMT is corroborated by a simultaneous reduction in the consumption of gasoline. Figure $\mathrm{A}$ in the Appendix shows the consumption of gasoline by week over 2007-2020. This weekly data shows a decrease in gasoline consumption of about $40 \%$ beginning in about mid-March. This decrease is well outside the historical norm, but is consistent with the drop in travel from the Unacast data.

We use fleet average emissions rates of $\mathrm{SO}_{2}, \mathrm{PM}_{2.5}, \mathrm{NO}_{\mathrm{X}}$, and volatile organic compounds (VOCs) to map the reduction in travel into the reduction in emissions. Emission rates for $\mathrm{PM}_{2.5}, \mathrm{NO}_{\mathrm{X}}$, and VOC are based on national average fleet characteristics and fuel properties in 2018 and are reported in Table 4-43 in NTS (2018). ${ }^{9}$ The emissions rate for $\mathrm{SO}_{2}$ assumes 22.3 fleet average mpg and $10 \mathrm{ppm}$ sulfur in gasoline, which reflects the latest gasoline sulfur content regulations. ${ }^{10}$ The resulting emissions rates (in grams per mile) are shown in Table 1 .

Emissions of different pollutants have different effects in different locations. The AP3 model accounts for dispersion of air pollution, atmospheric chemistry, dose-response relationships, and demographics of the affected populations to calculate the premature deaths from

\footnotetext{
${ }^{7}$ The robust standard errors for the confidence intervals are clustered at the state level and account for serial correlation and correlations across counties within a state.

${ }^{8}$ An F-test of an equal reduction during the last week of our data is rejected at the $5 \%$ level.

${ }^{9}$ We use the average of emission rates for light duty vehicles and light duty trucks.

${ }^{10}$ The fleet average mpg is for U.S. light duty vehicles in 2017 (BTS 2020). Carbon emissions per mile can be calculated from this mpg and the carbon content of gasoline.
} 
Figure 1: Effect of Social Distancing on Travel and Electricity Consumption



(a) Personal Vehicle Travel



(b) Electricity Consumption

Notes: Seven day moving averages. Data from Unacast (2020) and Cicala (2020). Early-policy states put a stay-at-home policy in place by March 28, 2020. Shaded area indicates 95 percent confidence interval. 
Table 1: U.S. Light Duty Vehicle Fleet Emissions Rates and Expected Death Rates

\begin{tabular}{lcc}
\hline \hline Pollutant & $\begin{array}{c}\text { Emissions } \\
(\mathrm{g} / \text { mile })\end{array}$ & $\begin{array}{c}\text { Deaths per } \\
\text { Billion Miles }\end{array}$ \\
\hline $\mathrm{SO}_{2}$ & 0.003 & 0.031 \\
$\mathrm{PM}_{2.5}$ & 0.013 & 0.469 \\
$\mathrm{NO}_{\mathbf{X}}$ & 0.384 & 1.944 \\
$\mathrm{VOC}$ & 0.386 & 0.632 \\
\hline
\end{tabular}

Notes: Deaths are VMT weighted averages across all counties in the contiguous U.S.

a unit of pollution emitted in each county. Hence, the model iterates over 3,100 counties and each pollutant in tabulating the premature deaths per unit of pollution. We summarize these damages in Table 1 which shows the VMT-weighted mean deaths per mile across all counties in the contiguous U.S. The table shows that $\mathrm{NO}_{\mathrm{X}}$ emissions are by far the most harmful pollutant from the current vehicle fleet resulting in almost two expected deaths per billion miles traveled. Conversely, the very low $\mathrm{SO}_{2}$ emission rates yield fewer deaths, per VMT, than $\mathrm{NO}_{\mathrm{X}}$. Combined, these four pollutants account for over three expected deaths per billion miles traveled. ${ }^{11}$

To calculate the reduction in expected deaths through reduced travel in a county because of social distancing, we simply multiply the county-level reduction in miles traveled (summarized in Figure 1a by the county-specific estimates of expected deaths per billion miles (summarized in Table 1). The reduction in expected deaths is mapped in Figure C in the Appendix. The reductions in deaths are the greatest in California's urban areas.

\section{$2.2 \quad$ Electricity use}

To estimate the health effects of reduced electricity usage, we combine estimates of the reduction in electricity use with estimates of the marginal health effects (marginal damage) per unit of power produced.

The reduction in electricity usage is estimated from data from individual Independent System Operators (ISOs) and the Energy Information Administration (EIA) on hourly electricity consumption, referred to as 'system load'. System load is the aggregate of all power

\footnotetext{
${ }^{11}$ Using the fleet average mpg and the carbon content of gasoline, we can also calculate the average $\mathrm{CO}_{2}$ emissions per mile.
} 
taken from the grid, including residential, commercial, and residential customers, as well as line loses. ISOs and the EIA vary in the geographic specificity of their reporting, ranging from zones covering local municipal utilities to the entire Tennessee Valley Authority. We refer to each reported unit as a Power Control Area (PCA) to simplify the distinction between types of load zones and balancing authorities. ${ }^{12}$

We match hourly load data to local temperature readings from the National Weather Service's Automated Surface Observing Systems (ASOS), a network of automated weather stations that are typically located at airports. These stations are matched to counties, and multiple stations' data are aggregated up to the PCA using population weights. To account for behind-the-meter generation, we also include hourly reports of solar generation for PCAs in California and New England.

To develop an estimate of reduced electricity consumption, we pool hourly readings of load and temperature from 2017-present. For each PCA, we regress the natural logarithm of hourly load on a set of day of week, hour of day, and week of year dummies. These control for the regular fluctuations in consumption that follow the clock and calendar. Hourly temperature data allow us to control for heating and cooling with the inclusion of a measure of prevailing temperature relative to 18 degrees Celsius (see Cicala (2020) for more details on the data assembly and estimation). Our estimate of the reduction in electricity consumption in a PCA is the remaining unexplained variation in electricity consumption, which is captured by a set of dummies for each date of interest.

Figure 1b summarizes these estimated reductions in electricity consumption by plotting the seven-day moving average of the load-weighted average coefficients across the PCAs. ${ }^{13}$ The results show that there are not reductions in electricity usage before early March but by mid-April reductions in electricity usage average about $6 \% .^{14}$

We estimate the health effects of these reductions in electricity consumption using a twostep procedure similar to that in Holland et al. (2020) for estimating marginal damages. The first step is to determine hourly expected deaths from pollution from power plants.

\footnotetext{
${ }^{12}$ In total there are 105 PCAs in our data.

${ }^{13}$ The robust standard errors for the confidence intervals are clustered at the PCA to account for serial correlation.

${ }^{14}$ Because PCA's can cross state boundaries, we do not break out the reduction by state stay-at-home policy.
} 
The second step is to determine the change in expected deaths from a change in electricity consumption.

In the first step, we use data reported from EPA's Continuous Emissions Monitoring System (CEMS) to measure hourly emissions of $\mathrm{SO}_{2}, \mathrm{NO}_{\mathrm{X}}$, and $\mathrm{PM}_{2.5}$ at each of the approximately 1500 fossil fuel fired power plants in the contiguous U.S. ${ }^{15,16}$ Holland et al. (2020) report a dramatic decline in emissions in recent years, so we use emissions from 2017, which is the most recent year in their dataset. Based on the location of each power plant, we use the AP3 model to map emissions of each pollutant into expected deaths. We then aggregate across pollutants and across power plants within an interconnection to calculate the hourly expected deaths from the pollution.

In the second step, we regress hourly expected deaths on hourly electricity load in each interconnection: East, West, and Texas. ${ }^{17}$ More specifically, let $D_{t}$ be the expected deaths in the interconnection due to emissions of all pollutants from all power plants in an interconnnection in hour $t$. Our estimating equation is

$$
D_{t}=\beta \operatorname{Load}_{t}+\alpha_{m h}+\epsilon_{t}
$$

where $\operatorname{Load}_{t}$ is electricity usage in the interconnnection in hour $t$ and $\alpha_{m h}$ are month of sample times hour fixed effects ( 1 year $* 12$ months $* 24$ hours fixed effects). The coefficient $\beta$ is the change in expected deaths from a change in electricity consumption in the interconnection. Table 2 shows the estimated coefficients and standard errors for each pollutant individually as well as in total. The East is the dirtiest interconnection with three expected deaths per TWh of electricity consumption. The bulk of the harm in the East comes from emissions of $\mathrm{SO}_{2}$. Marginal electricity consumption is least harmful in the West with less than one expected death per TWh of electricity consumption.

\footnotetext{
${ }^{15} \mathrm{SO}_{2}$ and $\mathrm{NO}_{\mathrm{X}}$ are directly reported, and we impute hourly $\mathrm{PM}_{2.5}$ emissions based on average emissions rates and observed hourly generation.

${ }^{16}$ CEMS also reports carbon emissions. We use a similar procedure to estimate marginal carbon emissions from a change in electricity usage.

${ }^{17}$ We aggregate deaths and load to the interconnection because electricity generally flows throughout an interconnection and PCA loads are highly correlated. See Holland et al. (2020).
} 
Table 2: Marginal Expected Deaths from Electricity Consumption

\begin{tabular}{lcccc}
\hline \hline Interconnection & Total & $\mathrm{SO}_{2}$ & $\mathrm{NO}_{\mathrm{X}}$ & $\mathrm{PM}_{2.5}$ \\
\hline East & 3.106 & 2.119 & 0.554 & 0.433 \\
& $(0.147)$ & $(0.134)$ & $(0.018)$ & $(0.008)$ \\
West & 0.849 & 0.255 & 0.297 & 0.297 \\
& $(0.026)$ & $(0.015)$ & $(0.011)$ & $(0.012)$ \\
Texas & 1.698 & 1.225 & 0.254 & 0.219 \\
& $(0.117)$ & $(0.106)$ & $(0.011)$ & $(0.009)$ \\
\hline
\end{tabular}

Notes: Expected deaths from electricity consumption in deaths per TWh. Newey-West standard errors (48 hour lag) in parentheses. Regressions include month of sample by hour fixed effects

To calculate the reduction in expected deaths through reduced electricity consumption from social distancing, we simply multiply the estimated reduction in electricity consumption at a PCA (summarized in Figure 1b) by the expected deaths per TWh in Table 2 for the appropriate interconnection. The reduction in expected deaths is mapped in Figure $\mathrm{D}$ in the Appendix. The reductions are the greatest in the Midwest and Southeast, but are much smaller than from reduced travel.

\section{Results}

Social distancing due to the COVID-19 outbreak led to reduced personal vehicle travel and electricity consumption which in turn lowered emissions of pollution and expected deaths. The overall effect of these changes, aggregated to the contiguous U.S., are shown in Table 3. Our baseline estimated number of expected deaths per month from air pollution from all light-duty vehicle travel is 666 expected deaths. Our estimated 40 percent average reduction in travel implies that the expected deaths is reduced by 314 deaths per month due to reduced travel. ${ }^{18}$ The table breaks the reduction in deaths into the precursor pollutant to which they can be attributed. Over half of the reduction in deaths are due to reduced $\mathrm{NO}_{\mathrm{x}}$ emissions but reductions in other pollutants such as VOCs and $\mathrm{PM}_{2.5}$ also contributed substantially. For electricity consumption, our baseline estimated number of expected deaths per month

\footnotetext{
${ }^{18}$ This $47 \%$ reduction in deaths indicates that travel reductions occurred disproportionately in high damage locations.
} 
from air pollution from electricity consumption is 859 deaths. This is a higher baseline than for travel, but the six percent reduction in electricity consumption implies that expected deaths are only reduced by 49 deaths (about 15\% of the reduction in deaths from travel). The primary reduction in deaths from electricity consumption can be attributed to reduced $\mathrm{SO}_{2}$ emissions. Combining the results for the reduction in travel and electricity usage gives a reduction of 363 expected deaths.

Table 3: Monthly Reduction in Deaths from Reduced Air Pollution

\begin{tabular}{lrrr}
\hline \hline & Travel & Electricity & Total \\
\hline Baseline Expected Deaths & 665.9 & 859.0 & $1,524.8$ \\
Average Percent Reduction & 41.0 & 6.2 & n.a. \\
Reduction in Expected Deaths & & & \\
Total & 313.8 & 48.8 & 362.6 \\
$\quad$ from $\mathrm{SO}_{2}$ & 3.1 & 32.7 & 35.8 \\
from $\mathrm{NO}_{\mathrm{X}}$ & 195.8 & 8.9 & 204.8 \\
from $\mathrm{PM}_{2.5}$ & 48.9 & 7.2 & 56.1 \\
from $\mathrm{VOC}$ & 66.0 & & 66.0 \\
\hline
\end{tabular}

Notes: Average percent reduction in travel is weighted by VMT. Average percent reduction in electricity is weighted by average load in 2019. Deaths are expected deaths per month.

The preceding analysis focuses on the expected health benefits from local pollutants of the reductions in personal vehicle travel and electricity consumption due to social distancing. Additionally, these reductions imply reductions in $\mathrm{CO}_{2}$ emissions which we can calculate using similar procedures. In particular, for travel we can use the carbon content of gasoline and the fleet mpg together with our estimated reduction in VMT to estimate the reduction in carbon emissions. Applying this methodology, we estimate that $\mathrm{CO}_{2}$ emissions were reduced by 35.4 million metric tons from a month of social distancing. For electricity consumption, we use the hourly power plant $\mathrm{CO}_{2}$ emissions from CEMS to estimate the marginal $\mathrm{CO}_{2}$ emissions from electricity consumption. Applying these estimates to our estimated reduction in electricity consumption in the various regions implies an aggregate reduction in $\mathrm{CO}_{2}$ emissions from power plants of 10.5 million metric tons from a month of social distancing. Combining the reductions in $\mathrm{CO}_{2}$ from travel and electricity consumption implies that the month of social distancing reduced $\mathrm{CO}_{2}$ emissions by 45.9 million metric 
tons. This is approximately $19 \%$ of the 242 million metric tons that are emitted monthly from driving and using electricity.

Social distancing was not evenly distributed across the country as some states and cities implemented stay-at-home policies while others did not. In addition, behavioral changes differed across regions, and mortality risks (as specified by the AP3 model) differ across counties. Table 4 shows the heterogeneity in the reduction in expected deaths and $\mathrm{CO}_{2}$ emissions due to the reduction in travel for the top MSAs and states. Social distancing in Los Angeles resulted in the largest reduction in expected deaths (77) and carbon emissions (1.1 million metric tons). New York City had a larger percentage reduction in travel but a smaller reduction in expected deaths (26) because of the lower number of baseline deaths per mile traveled. Behavioral changes in other large cities also induced substantial reductions in expected deaths and in $\mathrm{CO}_{2}$ emissions. At the state level, social distancing in California led to the largest reduction in deaths (115) and in $\mathrm{CO}_{2}$ emissions (4 million metric tons) from reduced travel.

Because the PCA's do not map cleanly into states and MSA's, we aggregate them into geographic areas based on Independent System Operators and NERC regions. The reduction in expected deaths and $\mathrm{CO}_{2}$ emissions from electricity consumption in these geographic areas are given in Table $\mathrm{C}$ in the Appendix. About half of the reductions in expected deaths and $\mathrm{CO}_{2}$ emissions comes from electricity consumption reductions in the Southeast and the Midwest (reduction of 13 and 12 deaths and 2.5 and 2.4 million metric tons of $\mathrm{CO}_{2}$ emissions). Although California had one of the larger percent reductions in electricity consumption (an 8 percent reduction), this reduction led to smaller declines in expected deaths and $\mathrm{CO}_{2}$ emissions due to cleaner electricity generation in the West.

\section{Conclusion}

Social distancing to control the spread of the novel coronavirus resulted in unprecedented changes in society and in economic activity. Among these are substantial changes in vehicle travel and in electricity usage. This paper quantifies reductions in travel and electricity usage relative to counterfactuals using highly-resolved data. We find that, at the county 
Table 4: Monthly Reduction in Deaths from Travel by MSA and State

\begin{tabular}{|c|c|c|c|c|c|}
\hline & $\begin{array}{r}\text { Monthly } \\
\text { VMT } \\
\text { (Billions) }\end{array}$ & $\begin{array}{r}\text { Baseline } \\
\text { Expected } \\
\text { Deaths }\end{array}$ & $\begin{array}{r}\text { Percent } \\
\text { Travel } \\
\text { Reduction }\end{array}$ & $\begin{array}{r}\text { Reduction } \\
\text { in Expected } \\
\text { Deaths }\end{array}$ & $\begin{array}{r}\text { Reduced } \\
\mathrm{CO}_{2} \\
\text { Emissions }\end{array}$ \\
\hline Total & 216.46 & 665.86 & 41.01 & 313.81 & 35.38 \\
\hline \multicolumn{6}{|l|}{ Top MSAs } \\
\hline Los Angeles & 5.83 & 157.37 & 48.68 & 76.61 & 1.13 \\
\hline New York City & 4.27 & 42.72 & 61.24 & 26.39 & 1.04 \\
\hline Chicago & 3.80 & 24.95 & 48.38 & 12.28 & 0.73 \\
\hline San Diego & 2.10 & 17.27 & 51.59 & 8.91 & 0.43 \\
\hline Santa Ana & 2.01 & 16.54 & 50.92 & 8.43 & 0.41 \\
\hline Atlanta & 4.17 & 15.44 & 44.65 & 7.41 & 0.74 \\
\hline Washington DC & 3.04 & 11.19 & 53.72 & 6.34 & 0.65 \\
\hline Philadelphia & 1.80 & 9.91 & 54.88 & 5.45 & 0.39 \\
\hline Newark & 1.39 & 9.19 & 56.21 & 5.31 & 0.31 \\
\hline Oakland (CA) & 1.62 & 10.53 & 50.30 & 5.25 & 0.32 \\
\hline Long Island & 1.44 & 7.71 & 53.23 & 4.34 & 0.31 \\
\hline Minneapolis & 2.30 & 8.33 & 49.97 & 4.31 & 0.46 \\
\hline Edison (NJ) & 1.67 & 7.64 & 52.90 & 4.05 & 0.35 \\
\hline Tampa & 1.98 & 8.38 & 46.60 & 4.03 & 0.37 \\
\hline San Jose & 1.18 & 6.10 & 57.88 & 3.56 & 0.27 \\
\hline \multicolumn{6}{|l|}{ Top States } \\
\hline California & 24.19 & 240.81 & 42.73 & 115.00 & 4.12 \\
\hline New York & 9.88 & 46.32 & 50.85 & 27.52 & 2.00 \\
\hline New Jersey & 5.56 & 32.85 & 52.76 & 17.95 & 1.17 \\
\hline Florida & 14.43 & 34.45 & 47.27 & 16.97 & 2.72 \\
\hline Illinois & 7.39 & 29.90 & 41.06 & 14.06 & 1.21 \\
\hline Pennsylvania & 7.21 & 22.97 & 42.67 & 10.80 & 1.23 \\
\hline Ohio & 9.13 & 25.61 & 38.76 & 10.43 & 1.41 \\
\hline Texas & 17.76 & 25.61 & 37.48 & 10.29 & 2.65 \\
\hline Michigan & 7.04 & 16.12 & 52.42 & 8.89 & 1.47 \\
\hline Georgia & 7.81 & 19.43 & 38.89 & 8.69 & 1.21 \\
\hline Maryland & 4.19 & 13.99 & 46.86 & 6.81 & 0.78 \\
\hline North Carolina & 7.83 & 15.41 & 36.23 & 5.85 & 1.13 \\
\hline Virginia & 6.39 & 12.67 & 40.48 & 5.73 & 1.03 \\
\hline Massachusetts & 4.12 & 9.91 & 50.78 & 5.12 & 0.83 \\
\hline Minnesota & 4.12 & 9.83 & 44.42 & 4.87 & 0.73 \\
\hline
\end{tabular}

Notes: Average travel reduction is weighted by VMT. Reduced $\mathrm{CO}_{2}$ emissions in millions of metric tons. 
level, average vehicle travel fell by about $40 \%$ whereas electricity usage dropped by about $6 \%$ during the months of March and April, 2020.

We then combine the estimated reductions in travel and electricity usage with air pollution emissions rates and the AP3 model, which links emissions to ambient concentrations and expected deaths. We find that the reductions in emissions from travel and electricity usage reduced deaths by over 360 deaths per month. The bulk of this reduction is attributed to less personal vehicle travel, and in particular reduced $\mathrm{NO}_{\mathrm{X}}$ emissions from this travel. Social distancing in California accounted for about a third of the reduction in deaths with Los Angeles alone contributing $20 \%$ of the national total. New York accounted for about $10 \%$ of the national total. Further, we estimate that social distancing resulted in approximately 46 million metric tons less $\mathrm{CO}_{2}$ emissions per month.

We note important caveats to our findings. First, the AP3 model uses concentrationresponse functions from the epidemiological literature (Krewski et al. 2009) that assume the incremental risk from exposure to $\mathrm{PM}_{2.5}$ is proportional to baseline mortality rates. Because of heightened mortality risk from COVID-19, our calculated reduction in deaths may significantly understate actual reductions in $\mathrm{PM}_{2.5}$ exposure risk. See the Appendix for a further discussion of this issue. In addition, our econometric estimation of counterfactual emissions and Unacast's estimates of counterfactual mobility are uncertain. Further, we are interpreting changes in cell phone mobility data as translating directly into changes in VMT from light-duty vehicles, and we do not model intermodal substitution from public transit to personal vehicle use. Finally, we cannot attribute the observed changes in travel and electricity usage to any specific policy or set of policies but only to behavioral changes as observed over this time frame.

Our work provides insight into the benefits and costs of policies related to social distancing (Thunstrom et al. 2020). Of course, the primary inputs to a benefit-cost analysis of social distancing would include avoided coronavirus infections, estimated in the trillions of dollars (Greenstone and Nigam 2020), and reduced economic activity. Our work augments these central arguments with one of the potentially many important non-market outcomes such as health, education, and the environment. Monetization facilitates inclusion of these health benefits directly into a benefit-cost analysis of social distancing. For example, if we assume 
a value of a statistical life (VSL) of $\$ 9$ million and a social cost of carbon of $\$ 50$ per ton, the national environmental benefit of social distancing is $\$ 5.5$ billion per month with about 60 percent of this benefit from reduced deaths. These benefits accrue substantially from social distancing in large metropolitan areas: about $\$ 750$ million per month from Los Angeles and about $\$ 320$ million per month from New York City.

Using observed behavioral changes, our paper demonstrates the degree to which reduced reliance on fossil-fuel based transport and power generation yields public health benefits. In the long run these findings are, perhaps, most interesting when interpreted in the context of a post-COVID-19 economy in which remote working and retail delivery are more common. In this state of the world as observed in early April 2020, power demand is only marginally affected, whereas personal travel declines appreciably. The paper shows significant local health benefits from this adjustment. The extent to which consumption habits revert to their pre-COVID-19 levels remains to be seen. 


\section{References}

[1] Allcott, Hunt, Levi Boxell, Jacob C. Conway, Matthew Gentzkow, Michael Thaler, and David Y. Yang (2020). "Polarization and Public Health: Partisan Differences in Social Distancing during the Coronavirus Pandemic" NBER Working Paper No. 26946.

[2] BTS (2020). "Average Fuel Efficiency of U.S.Light Duty Vehicles", https://www.bts. gov/content/average-fuel-efficiency-us-light-duty-vehicles.

[3] Briscese, Guglielmo , Nicola Lacetera, Mario Macis, and Mirco Tonin (2020). "Compliance with COVID-19 Social-Distancing Measures in Italy: The Role of Expectations and Duration" NBER Working Paper No. 26916.

[4] Cicala, Steve. (2020). "Early Economic Impacts of COVID-19: A View from the Grid", mimeo

[5] CDC (2020). "About Underlying Cause of Death, 1999-2018". https://wonder.cdc.g ov/ucd-icd10.html, Accessed 4/1/15.

[6] Clay, Karen, Akshaya Jha, N.Z. Muller, and Randy Walsh (2019). "The External Costs of Shipping Petroleum Products by Pipeline and Rail: Evidence of Shipments of Crude Oil from North Dakota." The Energy Journal. 40(1). 10.5547/01956574.40.1.kcla

[7] EIA (2020). "U.S. Weekly Product Supplied". https://www.eia.gov/dnav/pet/pet_c ons_wpsup_k_w.htm. Accessed 4/15/2020.

[8] EPA (2020). "Air Pollutant Emissions Trends Data". https://www.epa.gov/air-em issions-inventories/air-pollutant-emissions-trends-data

[9] Fang, Hanming, Long Wang, and Yang Yang (2020). "Human Mobility Restrictions and the Spread of the Novel Coronavirus (2019-nCoV) in China" NBER Working Paper No. 26906

[10] FERC (2020). "Form No. 714- Annual Electric Balancing Area and Planning Area Report (2020). https://www.ferc.gov/docs-filing/forms/form-714/data.asp Accessed 4/1/2020. 
[11] Friedson, Andrew I., Drew McNichols, Joseph J. Sabia, and Dhaval Dave (2020). "Did California's Shelter-in-Place Order Work? Early Coronavirus-Related Public Health Effects" NBER Working Paper No. 26992.

[12] Greenstone, Michael and Vishan Nigam (2020). "Does Social Distancing Matter?" University of Chicago, Becker Friedman Institute for Economics Working Paper No. 2020-26

[13] Krewski, Daniel, Michael Jerrett, Richard T Burnett, Renjun Ma, Edward Hughes, Yuanli Shi, Michelle C Turner, C Arden Pope III, George Thurston, Eugenia E Calle, et al. (2009). "Extended follow-up and spatial analysis of the American Cancer Society study linking particulate air pollution and mortality." Health Effects Institute. Boston, MA.

[14] Lepeule J, Laden F, Dockery D, Schwartz J. (2012). "Chronic exposure to fine particles and mortality: An extended follow-up of the Harvard six cities study from 1974 to 2009." Environ Health Perspect 120(7):965-970.

[15] Muller, N., R. Mendelsohn, and W. Nordhaus (2011). "Environmental Accounting for Pollution in the United States Economy." The American Economic Review, 101(5), 1649-1675.

[16] NTS (2018). "National Transportation Statistics", U.S. Department of Transportation, Bureau of Transportation Statistics, Washington D.C. https: //www.bts.gov/content/estimated-national-average-vehicle-emissions-r ates-vehicle-vehicle-type-using-gasoline-and.

[17] Streetlight (2020). VMT monitor by county. https://www.streetlightdata.com/vm t-monitor-by-county/

[18] Thunstrom, L., S. Newbold, D. Finnoff, M. Ashworth, and J. Shogren (2020). "The benefits and costs of using social distancing to flatten the curve for COVID-19", forthcoming, Journal of Benefit-Cost Analysis.

[19] Unacast (2020). "Social Distancing Scoreboard". https://www.unacast.com/covid1 9/social-distancing-scoreboard Accessed 4/18/20. 


\section{Appendices}

\section{Emissions from all sources}

Table A shows the tonnage of emissions of relevant criteria pollutants from the two broad source categories covered by this analysis. Electric power generation contributes about 1.1 million tons of $\mathrm{NO}_{\mathrm{x}}$ while highway vehicles (inclusive of light duty cars and heavy duty commercial trucks) emit another 3.3 million tons. Together these discharges amount to $43 \%$

of the national total emissions. Power generation and vehicle emissions of primary $\mathrm{PM}_{2.5}$ comprise just over $20 \%$ of total, national emissions. Releases of $\mathrm{SO}_{2}$ from these two source categories total up to about 1.3 million tons, or about half of the national total. And, for volatile organic compounds (VOCs) the total from power plants and vehicles is 1.6 million tons. This is $10 \%$ of national VOC emissions.

Table A: Overall Air Pollution Emissions by Source 2018

\begin{tabular}{lcccc}
\hline \hline Source & $\mathrm{NO}_{\mathrm{X}}$ & $\mathrm{PM}_{2.5}$ & $\mathrm{SO}_{2}$ & $\mathrm{VOC}$ \\
\hline Fuel Combustion: Electric Util. & 1114 & 182 & 1306 & 38 \\
Fuel Combustion: Industrial & 1143 & 224 & 534 & 110 \\
Fuel Combustion Other & 541 & 343 & 116 & 372 \\
Chemical \& Allied Product Mfg & 47 & 14 & 123 & 77 \\
Metals Processing & 70 & 44 & 105 & 29 \\
Petroleum \& Related Industries & 717 & 29 & 104 & 3145 \\
Other Industrial Processes & 330 & 265 & 167 & 346 \\
Solvent Utilization & 1 & 4 & 0 & 3052 \\
Storage \& Transport & 6 & 17 & 3 & 675 \\
Waste Disposal \& Recycling & 110 & 230 & 32 & 233 \\
Highway Vehicles & 3300 & 100 & 27 & 1609 \\
Off-Highway & 2653 & 173 & 69 & 1622 \\
Miscellaneous & 294 & 3689 & 150 & 4669 \\
\hline Total & 10327 & 5315 & 2735 & 15975 \\
\hline
\end{tabular}

Notes: Units are thousands of U.S. Short Tons. Data from EPA (2020).

\section{Weekly gasoline sales}

Figure A shows the sales of gasoline by week from 2007-2019 and the beginning of 2020 . Before 2020, the sales range between 8000 and 10,000 with an average around 9000 and a 
small peak in summer consumption (units are thousands of barrels per day). The first 11 weeks of 2020 are within this range, but starting with the 12th week (March 20) there is a precipitous drop down to about 5000. Sales remain depressed at this low level for the last three weeks of data (up to April 17).

Figure A: U.S. Product Supplied of Finished Motor Gasoline

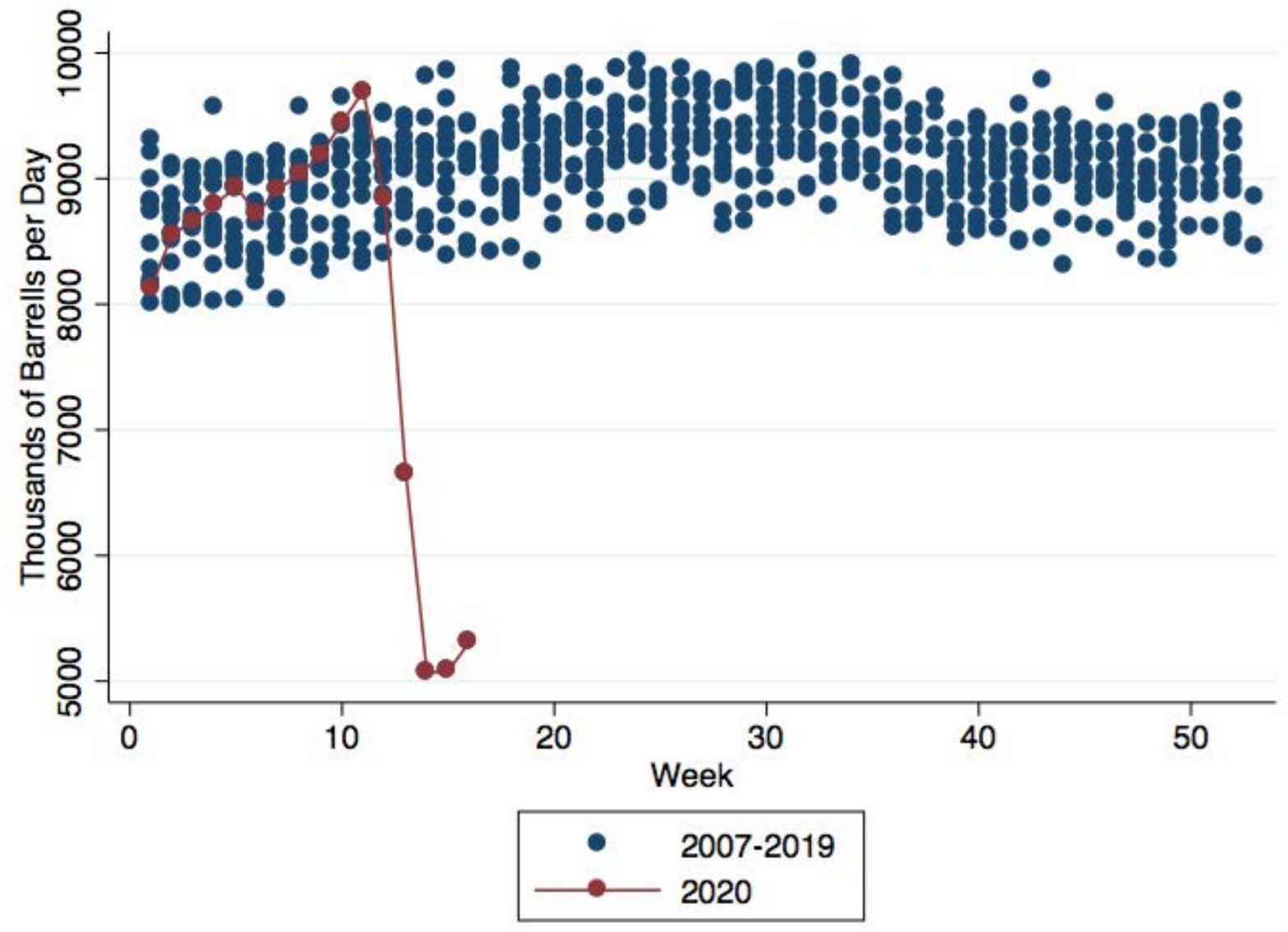

Notes: Data from EIA (2020). 


\section{Streetlight mobility data}

In the main text, we applied the travel reduction percentages from Unacast to the EPA's MOVES estimates of VMT. Alternatively, Streetlight (2020) uses cell phone mobility data to directly estimate reductions in VMT. An analogous figure to Figure 1a made using the Streetlight data is shown in Figure B. The results from using the Streetlight data to estimate the reduction in deaths from decreased air pollution are given in Table B. Compared to the results in the main text, the Streetlight data gives a greater decrease in VMT and hence a greater reduction in deaths. However, the decrease in the Streetlight VMT is larger than we would expect from the reduction in gasoline sales documented in Figure A, and the baseline estimate of total VMT in the Streetlight data is about 40 percent greater than

other estimates. For these reasons, we present the results from the Unacast data in the main text.

Table B: Reduction in Deaths from Reduced Air Pollution - StreetLight VMT Travel Data

\begin{tabular}{lrrr}
\hline \hline & Travel & Electricity & Total \\
\hline Baseline Lives Lost & 665.6 & 859.0 & $1,524.6$ \\
Average Percent Reduction & 66.9 & 6.2 & n.a. \\
Reduction in Lives Lost & & & \\
$\quad$ Total & 492.5 & 48.8 & 541.3 \\
$\quad$ from $\mathrm{SO}_{2}$ & 4.9 & 32.7 & 37.6 \\
$\quad$ from $\mathrm{NO}_{\mathrm{x}}$ & 309.9 & 8.9 & 318.9 \\
$\quad$ from $\mathrm{PM}_{2.5}$ & 75.7 & 7.2 & 82.9 \\
$\quad$ from $\mathrm{VOC}$ & 102.0 & & 102.0 \\
\hline
\end{tabular}

Notes: Average travel reduction is weighted by VMT. Baseline monthly deaths from travel is slightly lower than in Table 3 because there are more counties with missing data. 
Figure B: Reduction in StreetLight VMT Travel Data



Notes: Data from Streetlight (2020). Baseline is average daily VMT in January 2020. Seven day moving averages. Early-policy states put a stay-at-home policy in place by March 28, 2020. Shaded area shows 95 percent confidence interval. 


\section{Supplementary information about reductions in expected deaths}

Figures $[$ shows the reduction in deaths from reduced travel at the county level. The spatial distribution of the reduction in deaths depends on reduced travel from COVID-19, observed vehicle miles traveled, population exposure per ton of emissions, and demographics of the exposed population. Figure $\mathrm{D}$ shows the reduction in deaths from reduced electricity consumption at the PCA level. The spatial distribution depends on the reduction in electricity usage from COVID-19, the regional mix of fuels used to produce power, population exposure per ton of emissions, and demographics of the exposed population. These figures also illustrate that data is missing for a small number of counties. Table C shows the reduction in deaths aggregated to geographic regions based on a combination of ISO and NERC regions.

Figure C: Reduction in Deaths: Travel




Figure D: Reduction in Deaths: Electricity

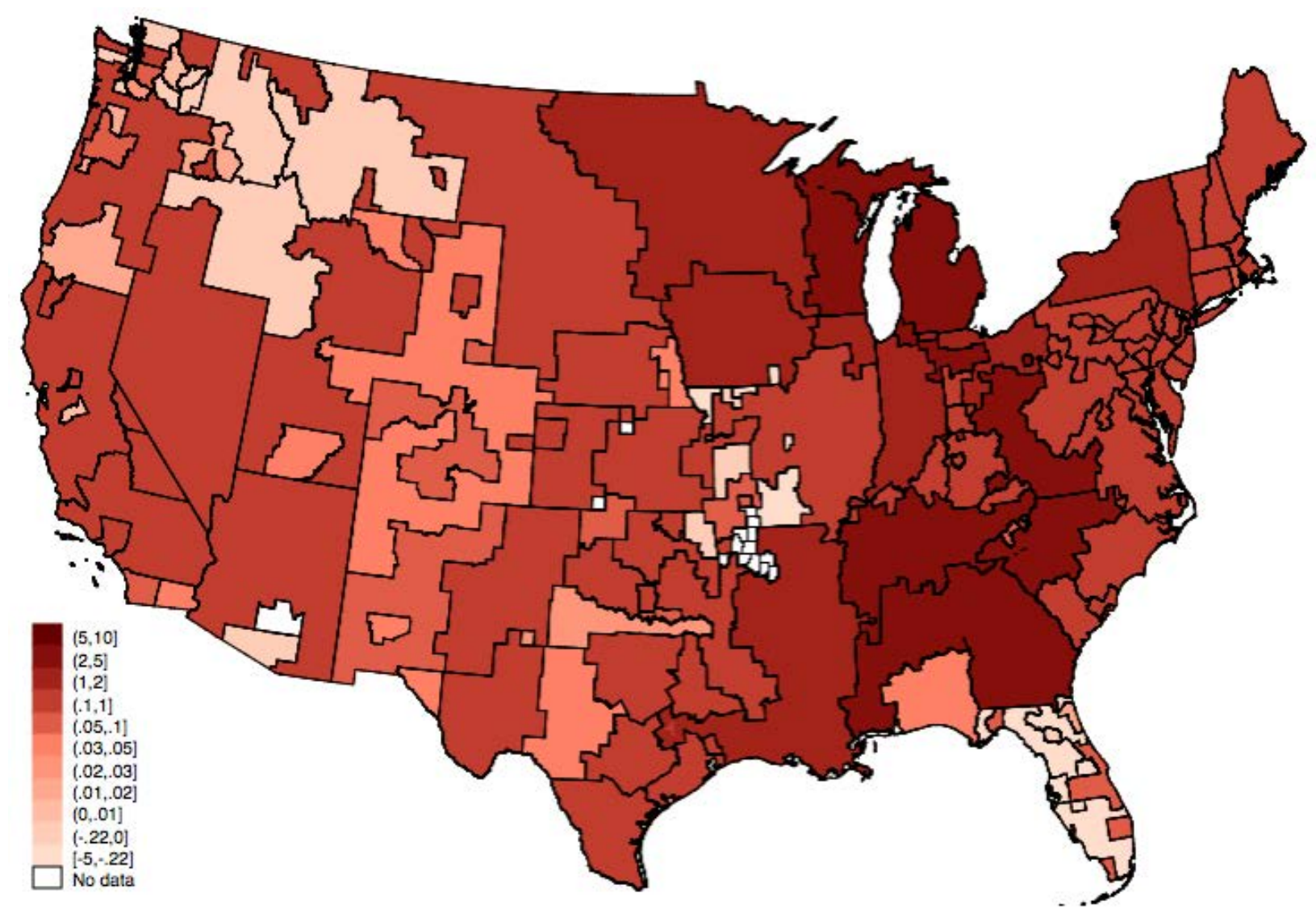

Table C: Monthly Reduction in Deaths From Electricity Generation

\begin{tabular}{lrrrrr}
\hline \hline & $\begin{array}{r}\text { Monthly } \\
\text { Consumption } \\
(\text { TWh })\end{array}$ & $\begin{array}{r}\text { Baseline } \\
\text { Expected } \\
\text { Deaths }\end{array}$ & $\begin{array}{r}\text { Percent } \\
\text { Electricity } \\
\text { Reduction }\end{array}$ & $\begin{array}{r}\text { Reduction } \\
\text { in Expected } \\
\text { Deaths }\end{array}$ & $\begin{array}{r}\text { Reduced } \\
\text { EOmissions }_{2}\end{array}$ \\
\hline Total & 332.23 & 858.96 & 6.20 & 48.84 & 10.47 \\
\hline Southeast Utilities & 54.98 & 170.77 & 8.91 & 13.13 & 2.55 \\
Midwest Market & 57.66 & 179.09 & 7.63 & 12.38 & 2.41 \\
MidAtlantic Market & 65.57 & 203.63 & 6.10 & 11.18 & 2.17 \\
Southwest Market & 22.54 & 69.99 & 6.11 & 3.92 & 0.76 \\
Texas Market & 31.97 & 54.30 & 6.66 & 3.29 & 0.92 \\
New York Market & 13.05 & 40.53 & 8.17 & 2.92 & 0.57 \\
New England Market & 9.77 & 30.34 & 5.32 & 1.43 & 0.28 \\
California Market & 18.17 & 15.42 & 7.61 & 1.02 & 0.56 \\
Western Utilities & 38.47 & 32.65 & 3.12 & 0.95 & 0.52 \\
Florida Utilities & 20.04 & 62.24 & -1.97 & -1.37 & -0.27 \\
\hline
\end{tabular}

Notes: California market is CAISO, Texas market is ERCOT, New England market is ISONE, Midwest market is MISO, New York market is NYISO, MidAtlantic market is PJM, Southwest market is SPP. For the others we aggregate PCAs by the NERC region: Florida (FRCC), Southeast (SERC), Western (WECC). Reduced $\mathrm{CO}_{2}$ emissions in millions of metric tons. 


\section{COVID-19 deaths and Total Respiratory Deaths}

There are aspects of $\mathrm{PM}_{2.5}$ and COVID-19 that require an important qualification, or caveat, to our findings. The epidemiological literature that establishes the association between $\mathrm{PM}_{2.5}$ and premature mortality repeatedly finds that risk from exposure is proportional to baseline mortality rates (Krewski et al., 2009; Lepeule et al., 2012). Because of this, our benefit estimates may significantly understate actual benefits. The estimated ambient pollution reductions have occurred during a period of time when baseline risks are elevated. We modeled the link between emissions and monetary damages with data from the most recent year comprehensive economy-wide emissions data are available, the 2014 model year. If risk from exposure is proportional to mortality rates in a given period, then it is quite likely that exposure during a period when mortality rates are elevated will yield a larger relative risk. Thus, damages will be higher in the elevated risk period.

To gauge how large this effect might be we gathered daily COVID-19 mortality data. Figure E shows the monthly mortality rates for COVID-19 deaths and for total respiratory deaths from 2018 (the most recent year for which month-by-county data are available) across all counties in the contiguous U.S. It shows that risks are clearly elevated during the COVID19 period (March and April, 2020). ${ }^{19}$ The population-weighted average COVID-19 fatality rate in April of 2020 is approximately three-times larger than the respiratory cause mortality rate, in April of 2018. However, severe COVID-19 outbreaks are highly concentrated in a few counties. Figure F depicts these cases. The intent is to convey how much baseline mortality rates have changed due to COVID-19, and what that adjustment might mean for concurrent benefits from $\mathrm{PM}_{2.5}$ reductions. The top-left panel shows the COVID-19 (April, 2020) and respiratory (April, 2018) rates for New York City. The difference in baseline risk is clear and extreme. Therefore, reductions in ambient $\mathrm{PM}_{2.5}$ may be severely underestimated in this area. Detroit (top right) shows a more modest (though still five fold) difference. These comparisons in Los Angeles and San Francisco reveal much smaller differences.

\footnotetext{
${ }^{19}$ The data are from CDC (2020).
} 
Figure E: COVID-19 (2020) and Total Respiratory Deaths (2018)



Notes: Red indicates deaths due to Covid, black indicates all respiratory deaths. Source CDC (2020). 
Figure F: COVID-19 (2020) and Total Respiratory Deaths (2018) In Selected Cities
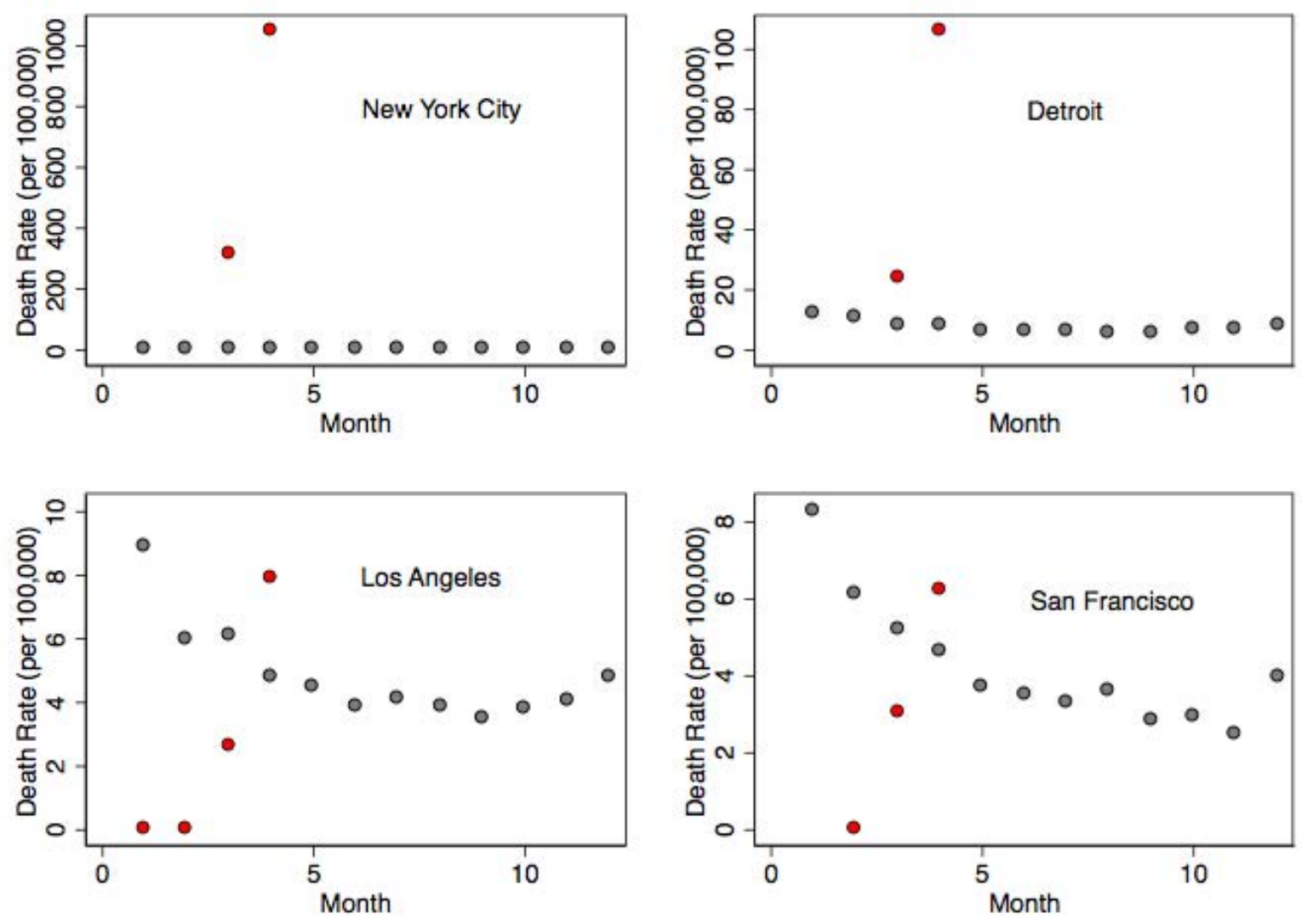

Notes: Red indicates deaths due to Covid, black indicates all respiratory deaths. Source CDC (2020). 